\title{
Factors Associated with and Temporal Trends in the Use of Radiation Therapy for the Treatment of Pituitary Adenoma in the National Cancer Database
}

\author{
${ }^{1}$ University of Pennsylvania Perelman School of Medicine, \\ Philadelphia, Pennsylvania, United States \\ 2 Department of Otolaryngology, University of California Irvine, \\ Irvine, California, United States \\ ${ }^{3}$ Department of Neurosurgery, Hospital of the University of \\ Pennsylvania, Philadelphia, Pennsylvania, United States \\ ${ }^{4}$ Department of Radiation Oncology, Hospital of the \\ University of Pennsylvania, Philadelphia, Pennsylvania, \\ United States \\ ${ }^{5}$ Department of Otorhinolaryngology, Hospital of the \\ University of Pennsylvania, Philadelphia, Pennsylvania, \\ United States \\ ${ }^{6}$ Department of Otorhinolaryngology Head and Neck Surgery, \\ Hospital of the University of Pennsylvania, Philadelphia, \\ Pennsylvania, United States
}

Ramie Fathy ${ }^{1}$ Edward Kuan ${ }^{20}$ John Y. K. Lee ${ }^{3}$ M Sean Grady ${ }^{3}$ Michelle Alonso-Basanta ${ }^{4}$ James N. Palmer ${ }^{5}$ Nithin D. Adappa ${ }^{6}$ Bert W. O’Malley Jr. ${ }^{6}$ Jason Brant ${ }^{6}$

Address for correspondence Ramie Fathy, $A B$, University of Pennsylvania Perelman School of Medicine, 3400 Civic Center Boulevard, Philadelphia, PA 19104, United States (e-mail: ramiefathy@gmail.com).

\begin{abstract}
Keywords

- radiation therapy

- pituitary adenoma

- national cancer database

- temporal trends

- radiation

- watchful waiting

- skull base

- anterior skull base

Objective Radiation therapy represents an uncommon but important component of treatment plans for some pituitary adenomas (PAs). Although radiation therapy has been used to treat pituitary adenomas for over a century, general trends in the usage of radiation therapy for this purpose have not been reviewed. Additionally, there are few large studies evaluating how radiation therapy is used for the treatment of these benign tumors. Investigating these trends and identifying any variations in radiation therapy utilization would help to better inform treatment decisions and improve patient outcomes.

Design Present study is a retrospective analysis of cases using the National Cancer Database.

Setting The research was organized at a tertiary academic medical center.

Participants Patients were diagnosed with pituitary adenoma between 2004 and 2014 within the National Cancer Database (NCDB).

Methods Temporal trends in the usage of radiation therapy to treat pituitary adenoma were analyzed through a retrospective analysis of 77,142 pituitary adenoma cases from the NCDB between 2004 and 2014. Univariate and multivariate analyses were to examine the relationship between patient, tumor, and treatment factors, and the incorporation of radiation therapy into the treatment of pituitary adenomas. We adjusted for potential confounders such as age, sex, race, comorbidity score, facility type, and year of diagnosis.
\end{abstract}

received

March 29, 2019

accepted after revision

July 28, 2019

published online

October 4, 2019 (c) 2019. Thieme. All rights reserved.

Georg Thieme Verlag KG,

Rüdigerstraße 14,

70469 Stuttgart, Germany
DOI https://doi.org/

10.1055/s-0039-1696724.

ISSN 2193-6331. 
Results A total of 77,142 patients met inclusion criteria. Inclusion of radiation therapy in pituitary adenoma treatment was $8.0 \%$ in 2004 and steadily declined to a low of $3.1 \%$ in 2014. Overall, patients were less likely to receive radiation for their pituitary adenoma over time $(p<0.001)$. Similarly, patients were found to be less likely to receive any type of treatment for PA over time $(p<0.001)$. Multivariable evaluation found patients who were female, between 54 and 64 years of age, or treated at either a Comprehensive Community Cancer Program or an Integrated Network Cancer Program were more likely to receive radiation as part of their pituitary adenoma treatment $(p<0.001$, odds ratio $[\mathrm{OR}]=2.01$, confidence interval $[\mathrm{Cl}]: 1.54-2.63 ; p<0.001$, $\mathrm{OR}=1.84, \mathrm{Cl}: 1.38-2.44$, respectively). Patients were less likely to receive radiation for their PA if they were African American ( $p<0.001, \mathrm{OR}=0.81, \mathrm{Cl}: 0.72-0.91)$. Logistic regression also identified a progressive increase in the likelihood of receiving radiation after a PA diagnosis with increasing tumor size starting with microscopic tumors, peaking at 4 to $5 \mathrm{~cm}(p<0.001 ; \mathrm{OR}=15.57 ; \mathrm{Cl}: 12.20-19.87)$.

Conclusion In this sample of pituitary adenoma patients treated at NCDB institutions between 2004 and 2014, we found a steady decline in the incorporation of radiation therapy in treatment, as well as in the use of any type of intervention for PA treatment, suggesting a rise in noninterventional observation of PA.

\section{Introduction}

Pituitary adenomas (PAs) are benign tumors that arise from the anterior pituitary gland. They represent between 10 and $20 \%$ of all primary brain tumors. ${ }^{1,2}$ These tumors can present in a variety of fashions; they may be discovered due to oversecretion of pituitary hormones or due to nonspecific symptoms arising due to a mass effect. Increasingly, they are incidentally identified in imaging studies, in which case they are commonly referred to as "incidentalomas."

Radiation therapy has played a central role in the treatment of PA for over a century, with Dr. Harvey Cushing outlining his then-revolutionary approach to treatment in his 1912 The Pituitary Body and Its Disorders: Clinical States Produced by Disorders of the Hypophysis Cerebri. ${ }^{3}$ Because of their size and location, pituitary adenomas are often difficult to resect surgically, and radiation therapy continues to be a common component of treatment plans for PA today.

Specifically, the standard primary treatment for all pituitary adenomas except for prolactinoma is surgery, with radiation being used for recurrent tumors or in cases where surgery may be risky (e.g., carotid or optic nerve encasement). Radiation treatment can be delivered via stereotactic radiosurgery (SRS) or fractionated radiation therapy (FRT). Furthermore, radiation offers local control rates between 90 and $100 \%$ for all types of PA, as well as biochemical complete response rates of approximately $50 \%$, which is augmented by the addition of medical therapies. ${ }^{4}$

With increased use and quality of imaging technologies, the diagnosis of PA has been increasing, and recent studies have reported its prevalence to be higher than previously believed. Unfortunately, due to a lack of mandatory reporting, prior studies using cancer registries, such as the Swedish National Cancer Registry, the Brain Tumor Registry of Japan, and the Central Brain Tumor Registry of the United States have been limited by under-reporting and consequently, unreliable or unrepresentative data. ${ }^{5-9}$ Due to this paucity of reliable, high-quality, large-volume studies, we are limited in our epidemiological understanding of PA, as well as our knowledge of trends in the use of radiation therapy to treat PA. ${ }^{10,11}$

Estimates from a 2004 meta-analysis of radiologic and autopsy studies predict that pituitary adenomas are present in approximately $16.7 \%$ of the general population. ${ }^{10}$ Studies on macroadenomas have estimated a prevalence between 0.16 to $0.3 \% .^{12-15}$

Although ionizing radiation is commonly used in medical treatment of pituitary adenomas and indications for its integration into a treatment regimen have been outlined, ${ }^{4}$ utilization of the treatment modality remains highly influenced by physician preference, and trends of radiation treatment for pituitary adenomas remain poorly characterized. Here, we analyze the NCDB database to identify temporal trends in the utilization of radiation therapy in the treatment of pituitary adenomas.

\section{Methods}

\section{Data Source}

Data were obtained from the NCDB on November 7, 2017 for patients with tumors of the head and neck diagnosed between 2004 and 2012. The NCDB is a joint project of the Commission on Cancer $(\mathrm{CoC})$ of the American College of Surgeons and the American Cancer Society, and data are collected from over 1,500 commission-accredited cancer programs representing approximately $30 \%$ of all hospitals in the United States and more than $70 \%$ of newly diagnosed cancer cases in the United States (www.facs.org/quality\%20programs/cancer/ncdb/). The 
CoC's NCDB and the hospitals participating in the CoC NCDB are the source of the deidentified data used herein; however, they have not verified and are not responsible for the statistical validity of the data analysis or the conclusions derived by the authors. This study was determined to be exempt by the Institutional Review Board of the Hospital of the University of Pennsylvania.

\section{Study Population}

Using the ICD-O-3 (International Classification of Diseases for Oncology, third ed.), the NCDB was queried for tumors of the pituitary gland (location code: C75.1) with histology codes corresponding to pituitary adenomas $(8140,8146,8260,8270$, $8271,8272,8280,8281,8290,8300$, and 8323). Cases that lacked values for either follow-up or vital status or that had a record of surgery at a distant site were excluded.

\section{Variables Analyzed}

The demographic and tumor variables analyzed included patient age at diagnosis, race, sex, medical comorbidities (Charlson-Deyo score, outlined in - Table $\mathbf{1}$ ), treatment facility type and tumor size. Race was categorized into White, Black, Asian, or other. Ethnicity was categorized as Hispanic or nonHispanic. Treatment facility type was categorized as follows: facility type was classified using the following method: community cancer program (100-500 newly diagnosed cancer cases per year), comprehensive community cancer program (>500 newly diagnosed cancer cases per year), academic cancer program ( $>500$ newly diagnosed cancer cases per year and at least four postgraduate medical education programs), or integrated network cancer program (owns, operates, leases, or is part of a joint venture with multiple facilities providing integrated cancer care and offers comprehensive services).

\section{Statistical Analysis}

The primary outcome of interest for this study was the incorporation of radiation therapy of any type into treatment

Table 1 Charlson-Deyo comorbidity score

\begin{tabular}{|l|l|}
\hline Score & Condition \\
\hline 1 & $\begin{array}{l}\text { Myocardial infarction } \\
\text { Congestive heart failure } \\
\text { Peripheral vascular disease } \\
\text { Dementia } \\
\text { Cerebrovascular disease } \\
\text { Chronic lung disease } \\
\text { Connective tissue disease } \\
\text { Peptic ulcer disease } \\
\text { Chronic liver disease } \\
\text { Diabetes }\end{array}$ \\
\hline 2 & $\begin{array}{l}\text { Diabetes with chronic complications } \\
\text { Hemiplegia or paraplegia } \\
\text { Renal disease }\end{array}$ \\
\hline 3 & Moderate or severe liver disease \\
\hline
\end{tabular}

Note: scores are summed for each patient and categorized by a value of $0,1,2$, or 3 or more. A zero score means that a patient did not have any of the conditions listed in the table. for pituitary adenoma, with a secondary endpoint being the type of radiation therapy used. Pearson's Chi-square tests were utilized for categorical variables and Mann-Whitney tests were used for continuous variables. Excluding cases lacking complete information, a multiple logistic regression model was performed to determine the independent factors associated with receipt of radiation for the treatment of pituitary adenoma. Variables included in the final multivariable Cox's proportional hazard model were age, sex, race, comorbidity score, facility location, tumor size, and year of diagnosis. The results were expressed as an odds ratio (OR) and a $95 \%$ confidence interval $(\mathrm{CI})$. All data processing and analysis were performed with Microsoft Open R v. 3.3.2 (https://mran.microsoft.com/open/) via RStudio v.1.1.23 (RStudio, Boston, Massachusetts, United States).

\section{Results}

\section{Demographics of Pituitary Adenoma in the United States}

A total of 80,287 cases of pituitary adenoma were identified in the NCDB, with 77,142 meeting the inclusion criteria. The number of cases of PA diagnosed per year increased from 4,410 in 2004 to 8,574 in 2014. - Table 2 outlines the demographic distribution of patients. The mean age at diagnosis was 50.88 years (standard deviation $[S D]=18.06$ ), and $53.9 \%$ of patients were female. Notably, the average age of men at diagnosis was older than that of women (54.9 vs. $47.5, p<0.001)$. The most commonly reported race was White (73.7\%). $36.6 \%$ of the patients received care in an academic program and the majority had a Charlson-Deyo comorbidity score of 0 (80.5\%).

\section{Trends in Radiation Therapy for Pituitary Adenomas}

Over the 10-year study period, 3,457 of the 77,142 patients (4.48\%) underwent radiation for their pituitary adenoma. While the proportion of patients receiving radiation peaked at $8.0 \%$ in 2004 , this proportion declined to $3.1 \%$ in 2014 $(p<0.001)$. This decline was still significant after controlling for patient, tumor, and treatment attributes. There was also a significant decrease in the overall treatment of pituitary adenoma during this time period, with $64.8 \%$ of patients receiving some sort of treatment in 2004 and 53.5\% undergoing treatment for their pituitary adenoma in 2014 $(p<0.001$; - Fig. 1 and - Table 3$)$.

The second primary endpoint of this study was the radiation modality employed to treat pituitary adenoma. Information regarding the type of radiation administered to patients was available for 3,439 cases, constituting $99.5 \%$ of the patients who received radiation for PA. Overall, the most commonly used radiation modality during the study period was External Beam Radiation Therapy (EBRT) which was utilized for $63.1 \%$ of these. Similar to the proportion of patients receiving radiation, the distribution in types of radiation used also shifted over the 10 years analyzed in this study (- Fig. 2 and - Table 4). In 2004, EBRT was used for $69.4 \%$ of cases, significantly declining to $60.5 \%$ of cases in $2014(p=0.027)$. Stereotactic radiosurgery, on the other 
Table 2 Patient and tumor characteristics of 77,142 cases of $\mathrm{PA}$ in the NCDB

\begin{tabular}{|c|c|c|}
\hline & $n$ & $\%$ \\
\hline \multicolumn{3}{|l|}{ Age (y) } \\
\hline$<54$ & 43,356 & 56.2 \\
\hline $54-64$ & 14,187 & 18.4 \\
\hline $64-74$ & 11,543 & 15.0 \\
\hline $74-100$ & 8,046 & 10.4 \\
\hline \multicolumn{3}{|l|}{ Gender } \\
\hline Male & 35,577 & 46.1 \\
\hline Female & 41,565 & 53.9 \\
\hline \multicolumn{3}{|l|}{ Race } \\
\hline White/Caucasian & 56,855 & 73.7 \\
\hline African American & 14,678 & 19 \\
\hline Asian & 2,638 & 3.4 \\
\hline Other/unknown & 2,970 & 3.9 \\
\hline \multicolumn{3}{|l|}{ Ethnicity } \\
\hline Hispanic & 8,194 & 10.6 \\
\hline Non-Hispanic & 64,990 & 84.2 \\
\hline Unknown & 3,958 & 5.1 \\
\hline \multicolumn{3}{|l|}{ Facility type } \\
\hline Academic/research & 28,213 & 36.6 \\
\hline $\mathrm{CCC}$ & 17,185 & 22.3 \\
\hline Integrated network & 7,011 & 9.1 \\
\hline Community & 2,454 & 3.2 \\
\hline \multicolumn{3}{|l|}{ Charlson-Deyo } \\
\hline 0 & 62,101 & 80.5 \\
\hline 1 & 11,542 & 15.0 \\
\hline 2 & 2,532 & 3.3 \\
\hline 3 & 967 & 1.3 \\
\hline \multicolumn{3}{|l|}{ Tumor size } \\
\hline$<1 \mathrm{~cm}$ & 16,935 & 22.0 \\
\hline $1-2 \mathrm{~cm}$ & 16,815 & 21.8 \\
\hline $2-3 \mathrm{~cm}$ & 15,715 & 20.4 \\
\hline $3-4 \mathrm{~cm}$ & 7,080 & 9.2 \\
\hline $4-5 \mathrm{~cm}$ & 2,472 & 3.2 \\
\hline $5-6 \mathrm{~cm}$ & 884 & 1.1 \\
\hline$>6 \mathrm{~cm}$ & 1,324 & 1.7 \\
\hline
\end{tabular}

Abbreviations: CCC, community cancer center; NCBD, national cancer database; PA, pituitary adenoma.

hand, was used for $30.0 \%$ of cases in 2004 but was employed for $39.5 \%$ of cases in 2014 ( $p=0.018$ ).

\section{Factors Associated with Radiation Therapy for Pituitary Adenoma}

Overall, 3,457 patients (4.5\%) received radiation therapy as part of their initial treatment for their PA. Mean time from diagnosis to the initiation of radiation was 154 days with a standard deviation of 192 days. Median time from diagnosis to radiation was 119 days with interquartile range of 117 days.

A multivariable logistic regression model for the factors associated with receiving radiation was conducted for the 61,225 patients with complete data and is shown in - Table 5 and - Fig. 3. Over time, patients were significantly less likely to receive radiation for their PA $(p<0.001)$. Additionally, females were more likely to receive radiation than males $(p<0.001, \mathrm{OR}=1.24, \mathrm{CI}: 1.14-1.37)$. Compared with patients under 54 years of age, patients between 54 and 64 years old were more likely to receive radiation $(p<0.001$, OR $=1.19$, CI: 1.06-1.33).

Relative to White patients, African American patients were less likely to receive radiation $(p<0.001, \mathrm{OR}=0.81$, CI: $0.72-.91)$. Patients with macroadenomas ( $>1 \mathrm{~cm}$ in size) were significantly more likely to receive radiation than patients with microadenomas $(p<0.001)$.

Patients who were treated at a Comprehensive Community Cancer Program or an Integrated Network Cancer Program were more likely to receive radiation for their PA than patients treated at a Community Cancer Program $(p<0.001, \mathrm{OR}=2.01$, CI: $1.54-2.63 ; p<0.001, \mathrm{OR}=1.84, \mathrm{CI}: 1.38-2.44$, respectively).

With regard to tumor size, the logistic regression identified a progressive increase in the likelihood of receiving radiation after a PA diagnosis with increasing tumor size starting with microscopic tumors, peaking at 4 to $5 \mathrm{~cm}(p<0.001$; OR $=15.57$; CI: $12.20-19.87$ ), and then progressively decreasing with tumors beyond that size. Extending the multivariable model to consider factors associated with receiving any type of treatment for PA identified a similar pattern, with a slightly shifted peak corresponding to tumor sizes between 3 and $4 \mathrm{~cm}$ $(p<0.001 ; \mathrm{OR}=5.12 ; \mathrm{CI}: 4.72-5.56 ;$ - Table 6).

\section{Discussion}

Pituitary adenoma is a relatively common, benign tumor of the anterior pituitary gland, and it has an extensive history of advances in its treatment and outcomes. It is also among the first benign tumor types to be treated primarily with radiation, and as more PA patients are treated with radiation, there is a growing population of individuals with prior pituitary irradiation who may suffer from potential late toxicities of such radiation. However, despite the longstanding relationship between PA and radiation, we lack a comprehensive understanding of actual rates of radiation utilization for PA treatment, as well as the factors that influence this relationship. This is largely due to limitations of prior studies on the subject, which include under-reporting, short-study periods, or relatively small sample sizes. ${ }^{8}$ Greater information on these management patterns could inform the development of more standardized and reliable national treatment guidelines which would prevent potentially detrimental variation in the quality or intensity of treatment plans across the country.

This study represents the largest review of trends in the management of PA in the United States, to date and to our knowledge, the first to use the NCDB to do so, as well as the first to describe temporal patterns, in the use of radiation therapy for all types of PA. Using the NCDB, we were able to 


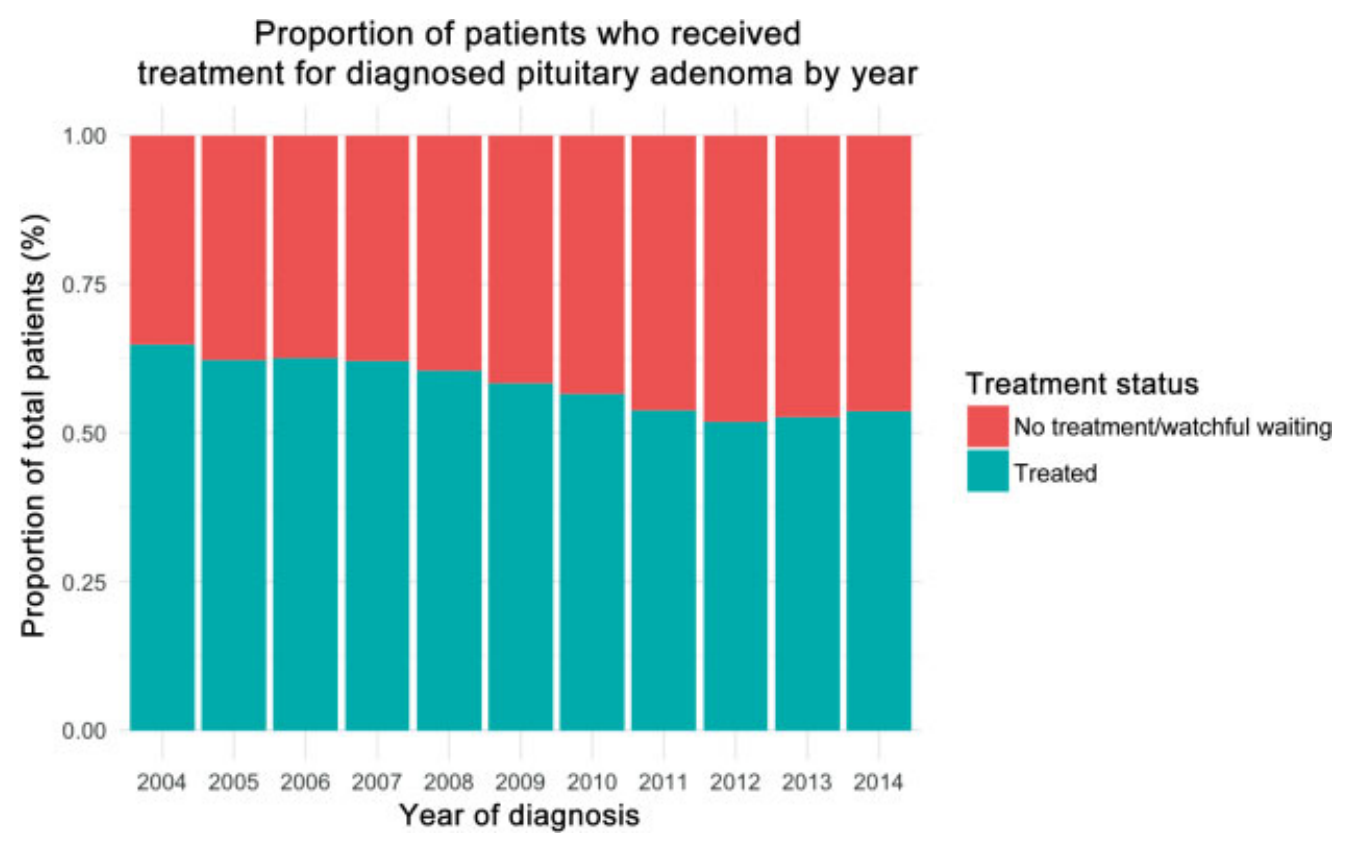

Fig. 1 Distribution of pituitary adenoma patients who were treated with medical, surgical, or radiation therapy or watchful waiting between 2004 and 2014.

Table 3 Distribution of pituitary adenoma patients who were treated with medical, surgical, or radiation therapy or watchful waiting between 2004 and 2014

\begin{tabular}{|l|l|l|l|l|l|l|l|l|l|l|l|l|}
\hline & level & $\mathbf{2 0 0 4}$ & $\mathbf{2 0 0 5}$ & $\mathbf{2 0 0 6}$ & $\mathbf{2 0 0 7}$ & $\mathbf{2 0 0 8}$ & $\mathbf{2 0 0 9}$ & $\mathbf{2 0 1 0}$ & $\mathbf{2 0 1 1}$ & $\mathbf{2 0 1 2}$ & $\mathbf{2 0 1 3}$ & $\mathbf{2 0 1 4}$ \\
\hline$n$ & & 4,294 & 5,036 & 5,550 & 6,109 & 6,623 & 7,426 & 7,540 & 7,942 & 8,600 & 8,605 & 8,537 \\
\hline $\begin{array}{l}\text { Treated } \\
\text { tsatus } \\
(\%)\end{array}$ & $\begin{array}{l}\text { No treatment/ } \\
\text { watchful } \\
\text { waiting }\end{array}$ & $\begin{array}{l}1,510 \\
(35.2)\end{array}$ & $\begin{array}{l}1,899 \\
(37.7)\end{array}$ & $\begin{array}{l}2,082 \\
(37.5)\end{array}$ & $\begin{array}{l}2,314 \\
(37.9)\end{array}$ & $\begin{array}{l}2,622 \\
(39.6)\end{array}$ & $\begin{array}{l}3,096 \\
(41.7)\end{array}$ & $\begin{array}{c}3,276 \\
(43.4)\end{array}$ & $\begin{array}{l}3,671 \\
(46.2)\end{array}$ & $\begin{array}{l}4,141 \\
(48.2)\end{array}$ & $\begin{array}{l}4,075 \\
(47.4)\end{array}$ & 3,966 \\
$(46.5)$ \\
\hline$n(\%)$ & Treated & 2,784 & 3,137 & 3,468 & 3,795 & 4,001 & 4,330 & 4,264 & 4,271 & 4,459 & 4,530 & 4,571 \\
& & $(64.8)$ & $(62.3)$ & $(62.5)$ & $(62.1)$ & $(60.4)$ & $(58.3)$ & $(56.6)$ & $(53.8)$ & $(51.8)$ & $(52.6)$ & $(53.5)$ \\
\hline
\end{tabular}

Type of radiation therapy used by year

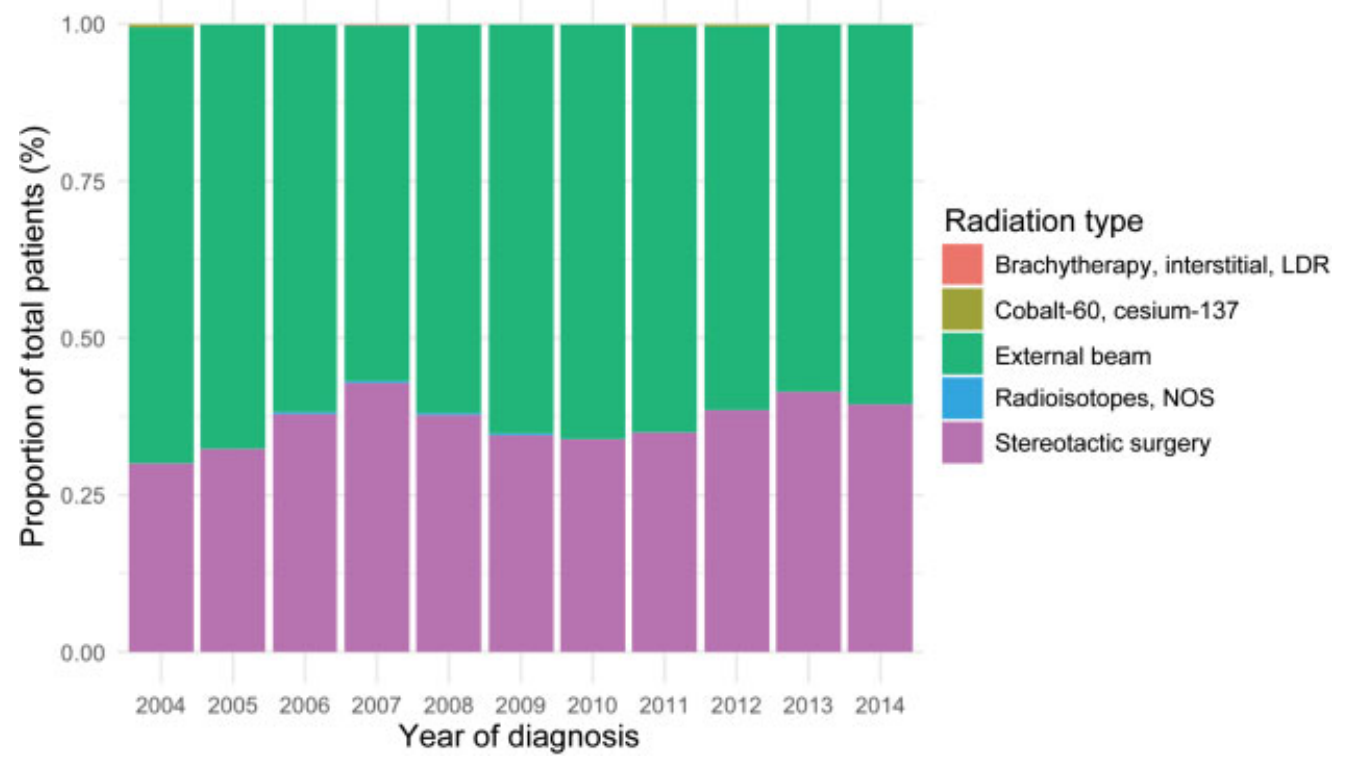

Fig. 2 Distribution of radiation therapy modality utilized for 3,439 cases of pituitary adenoma between 2004 and 2014. NOS, not otherwise specified. 
Table 4 Radiation therapy modality usage over time for 3,439 cases with available data in the NCDB

\begin{tabular}{|c|c|c|c|c|c|c|c|c|c|c|c|c|}
\hline & & 2004 & 2005 & 2006 & 2007 & 2008 & 2009 & 2010 & 2011 & 2012 & 2013 & 2014 \\
\hline$n$ & & 350 & 313 & 330 & 360 & 368 & 339 & 281 & 283 & 283 & 266 & 266 \\
\hline \multirow[t]{5}{*}{$\begin{array}{l}\text { Radiation } \\
\text { type } \\
\text { (\%) }\end{array}$} & $\begin{array}{l}\text { Brachytherapy, } \\
\text { interstitial, LDR }\end{array}$ & $\begin{array}{l}0 \\
(0.0)\end{array}$ & $\begin{array}{l}0 \\
(0.0)\end{array}$ & $\begin{array}{l}0 \\
(0.0)\end{array}$ & $\begin{array}{l}1 \\
(0.3)\end{array}$ & $\begin{array}{l}0 \\
(0.0)\end{array}$ & $\begin{array}{l}0 \\
(0.0)\end{array}$ & $\begin{array}{l}0 \\
(0.0)\end{array}$ & $\begin{array}{l}0 \\
(0.0)\end{array}$ & $\begin{array}{l}0 \\
(0.0)\end{array}$ & $\begin{array}{l}0 \\
(0.0)\end{array}$ & $\begin{array}{l}0 \\
(0.0)\end{array}$ \\
\hline & $\begin{array}{l}\text { Cobalt-60, } \\
\text { cesium-137 }\end{array}$ & $\begin{array}{l}2 \\
(0.6)\end{array}$ & $\begin{array}{l}0 \\
(0.0)\end{array}$ & $\begin{array}{l}0 \\
(0.0)\end{array}$ & $\begin{array}{l}0 \\
(0.0)\end{array}$ & $\begin{array}{l}0 \\
(0.0)\end{array}$ & $\begin{array}{l}0 \\
(0.0)\end{array}$ & $\begin{array}{l}0 \\
(0.0)\end{array}$ & $\begin{array}{l}1 \\
(0.4)\end{array}$ & $\begin{array}{l}1 \\
(0.4)\end{array}$ & $\begin{array}{l}0 \\
(0.0)\end{array}$ & $\begin{array}{l}0 \\
(0.0)\end{array}$ \\
\hline & $\begin{array}{l}\text { External } \\
\text { beam }\end{array}$ & $\begin{array}{l}243 \\
(69.4)\end{array}$ & $\begin{array}{l}212 \\
(67.7)\end{array}$ & $\begin{array}{l}204 \\
(61.8)\end{array}$ & $\begin{array}{l}204 \\
(56.7)\end{array}$ & $\begin{array}{l}228 \\
(62.0) \\
\end{array}$ & $\begin{array}{l}221 \\
(65.2)\end{array}$ & $\begin{array}{l}186 \\
(66.2)\end{array}$ & $\begin{array}{l}183 \\
(64.7)\end{array}$ & $\begin{array}{l}173 \\
(61.1)\end{array}$ & $\begin{array}{l}156 \\
(58.6)\end{array}$ & $\begin{array}{l}161 \\
(60.5)\end{array}$ \\
\hline & $\begin{array}{l}\text { Radioisotopes, } \\
\text { NOS }\end{array}$ & $\begin{array}{l}0 \\
(0.0)\end{array}$ & $\begin{array}{l}0 \\
(0.0)\end{array}$ & $\begin{array}{l}1 \\
(0.3)\end{array}$ & $\begin{array}{l}1 \\
(0.3)\end{array}$ & $\begin{array}{l}1 \\
(0.3)\end{array}$ & $\begin{array}{l}1 \\
(0.3)\end{array}$ & $\begin{array}{l}0 \\
(0.0)\end{array}$ & $\begin{array}{l}0 \\
(0.0)\end{array}$ & $\begin{array}{l}0 \\
(0.0)\end{array}$ & $\begin{array}{l}0 \\
(0.0)\end{array}$ & $\begin{array}{l}0 \\
(0.0)\end{array}$ \\
\hline & $\begin{array}{l}\text { Stereotactic } \\
\text { surgery }\end{array}$ & $\begin{array}{l}105 \\
(30.0)\end{array}$ & $\begin{array}{l}101 \\
(32.3)\end{array}$ & $\begin{array}{l}125 \\
(37.9)\end{array}$ & $\begin{array}{l}154 \\
(42.8)\end{array}$ & $\begin{array}{l}139 \\
(37.8)\end{array}$ & $\begin{array}{l}117 \\
(34.5)\end{array}$ & $\begin{array}{l}95 \\
(33.8)\end{array}$ & $\begin{array}{l}99 \\
(35.0)\end{array}$ & $\begin{array}{l}109 \\
(38.5)\end{array}$ & $\begin{array}{l}110 \\
(41.4)\end{array}$ & $\begin{array}{l}105 \\
(39.5)\end{array}$ \\
\hline
\end{tabular}

Abbreviations: LDR, low dose rate; NCBD, national cancer database.

Table 5 Factors associated with likelihood of receiving radiation after PA diagnosis

\begin{tabular}{|c|c|c|c|}
\hline & OR & $95 \% \mathrm{Cl}$ & p-Value \\
\hline \multicolumn{4}{|c|}{ Year of diagnosis } \\
\hline 2004 & 1 & Reference & - \\
\hline 2005 & 0.84 & $0.68-1.05$ & 0.13 \\
\hline 2006 & 0.80 & $0.64-0.99$ & 0.039 \\
\hline 2007 & 0.78 & $0.62-0.97$ & 0.023 \\
\hline 2008 & 0.76 & $0.62-0.94$ & 0.010 \\
\hline 2009 & 0.66 & $0.54-0.82$ & $<0.001$ \\
\hline 2010 & 0.51 & $0.41-0.63$ & $<0.001$ \\
\hline 2011 & 0.48 & $0.39-0.60$ & $<0.001$ \\
\hline 2012 & 0.43 & $0.35-0.53$ & $<0.001$ \\
\hline 2013 & 0.40 & $0.32-0.49$ & $<0.001$ \\
\hline 2014 & 0.40 & $0.32-00.50$ & $<0.001$ \\
\hline \multicolumn{4}{|l|}{ Age $(y)$} \\
\hline$<4$ & 1 & Reference & - \\
\hline $54-64$ & 1.19 & $1.06-1.33$ & 0.002 \\
\hline $64-74$ & 1.11 & $0.98-1.26$ & 0.089 \\
\hline $74-100$ & 0.92 & $0.79-1.06$ & 0.25 \\
\hline \multicolumn{4}{|l|}{ Gender } \\
\hline Male & 1 & Reference & - \\
\hline Female & 1.24 & $1.14-1.37$ & $<0.001$ \\
\hline \multicolumn{4}{|c|}{ Tumor Size $(\mathrm{cm})$} \\
\hline$<1$ & 1 & Reference & - \\
\hline $1-2$ & 3.14 & $2.5-3.94$ & $<0.001$ \\
\hline $2-3$ & 5.22 & $4.2-6.50$ & $<0.001$ \\
\hline $3-4$ & 9.31 & $7.45-11.66$ & $<0.001$ \\
\hline $4-5$ & 15.57 & $12.20-19.87$ & $<0.001$ \\
\hline $5-6$ & 13.63 & 9.97-18.66 & $<0.001$ \\
\hline$>6$ & 7.41 & $5.36-10.27$ & $<0.001$ \\
\hline
\end{tabular}

Table 5 (Continued)

\begin{tabular}{|l|l|l|l|}
\hline & OR & $95 \% \mathrm{Cl}$ & $\mathrm{p}$-Value \\
\hline Race & & & \\
\hline White/Caucasian & 1 & Reference & - \\
\hline African American & $\mathbf{0 . 8 1}$ & $\mathbf{0 . 7 2 - 0 . 9 1}$ & $<\mathbf{0 . 0 0 1}$ \\
\hline Asian & 0.97 & $0.76-1.23$ & 0.80 \\
\hline Other/unknown & 0.81 & $0.61-1.06$ & 0.12 \\
\hline Facility type & & & \\
\hline Community & 1 & Reference & - \\
\hline CCC & 2.01 & $1.54-2.63$ & $<\mathbf{0 . 0 0 1}$ \\
\hline Integrated network & 1.84 & $1.38-2.44$ & $<\mathbf{0 . 0 0 1}$ \\
\hline Academic/research & 1.23 & $0.94-1.61$ & 0.13 \\
\hline Charlson-Deyo & & & \\
\hline 0 & 1 & Reference & - \\
\hline 1 & 0.93 & $0.83-1.05$ & 0.23 \\
\hline 2 & 0.80 & $0.63-1.01$ & 0.06 \\
\hline 3 & $\mathbf{0 . 4 9}$ & $\mathbf{0 . 3 0 - 0 . 7 8}$ & $\mathbf{0 . 0 0 3}$ \\
\hline
\end{tabular}

Abbreviations: CCC, comprehensive community cancer program; $\mathrm{Cl}$, confidence interval; OR, odds ratio.

Note: Bold rows represent a significant difference the $p<0.05$ level.

identify several factors that predict the use of radiation therapy for PA treatment, as well as general trends, in the utilization of radiation therapy for PA.

We observed an increasing incidence of PA during the time period. This finding is in line with similar observations reported in other studies. ${ }^{5}$ As suggested by others, this increase is likely due to improvements in imaging modalities and diagnostic techniques, which would result in a higher rate of incidentally identified PAs, or "incidentalomas." With additional institutions reporting to the NCDB over time, this could also account for increased numbers of documented PA cases each year. The increase in the reported number of PAs is also likely a result of additional reporting centers joining the 

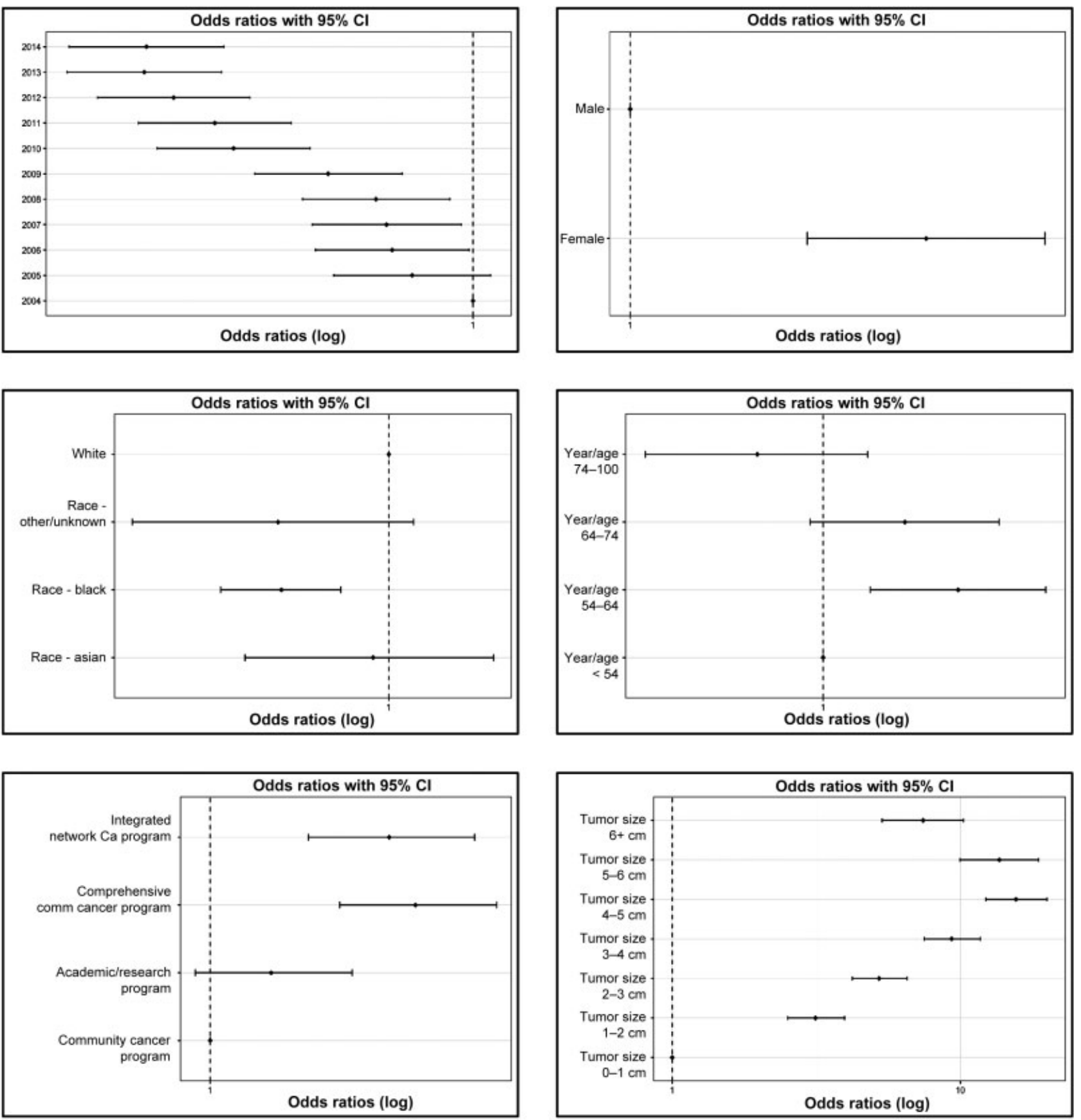

Fig. 3 Probability of receiving radiation therapy for pituitary adenoma in a multivariable model. Cl, confidence interval.

NCDB each year. With more sites participating in the database, more cases could be captured and reported each year, resulting in an apparent increase in the number of overall cases per year over time.

With regard to its utilization for PA treatment, radiation therapy experienced a significant decline between 2004 and 2014. More generally, patients with PA were also found to be increasingly less likely to receive any type of treatment over time. These findings may be the result of several potential mechanisms. First, as diagnostic modalities improve and a greater number of adenomas are identified incidentally, without any associated symptoms or potentially harmful hormone release, a rise in the number of unsymptomatic PAs that are managed conservatively may underlie the overall lower rate of PAs that receive some sort of treatment. ${ }^{5}$ Alternatively, as the natural history of PAs is better understood over time, there may be a rise in "watchful waiting," or noninterventional monitoring of PAs, which may not progress in a clinically significant fashion or may be in a location that poses a high perioperative risk. ${ }^{16} \mathrm{~A}$ recent study on the natural history of clinically nonfunctioning pituitary incidentalomas reported a tumor growth rate of only $4 \%$ in the year following the incidental diagnosis, supporting the practice of noninterventional monitoring of such tumors. ${ }^{17}$ Similarly, because of the potential long-term effects of radiation and the strong association of hypopituitarism following 
Table 6 Factors associated with likelihood of receiving any type of treatment (medical, surgical, and radiation) after PA diagnosis

\begin{tabular}{|c|c|c|c|}
\hline & OR & $95 \% \mathrm{Cl}$ & $p$-Value \\
\hline \multicolumn{4}{|l|}{ Year of diagnosis } \\
\hline 2004 & 1 & Reference & - \\
\hline 2005 & 0.93 & $0.81-1.07$ & 0.328 \\
\hline 2006 & 0.92 & $0.91-1.06$ & 0.251 \\
\hline 2007 & 0.99 & $0.87-1.13$ & 0.889 \\
\hline 2008 & 0.96 & $0.84-1.09$ & 0.541 \\
\hline 2009 & 0.93 & $0.82-1.05$ & 0.258 \\
\hline 2010 & 0.84 & $0.74-0.95$ & 0.006 \\
\hline 2011 & 0.83 & $0.74-0.94$ & 0.004 \\
\hline 2012 & 0.83 & $0.74-0.94$ & 0.003 \\
\hline 2013 & 0.87 & $0.77-0.98$ & 0.022 \\
\hline 2014 & 0.93 & $0.82-1.05$ & 0.23 \\
\hline \multicolumn{4}{|l|}{ Age (y) } \\
\hline$<54$ & 1 & Reference & - \\
\hline $54-64$ & 0.86 & $0.81-0.91$ & $<0.001$ \\
\hline $64-74$ & 0.63 & $0.59-0.67$ & $<0.001$ \\
\hline $74-100$ & 0.25 & $0.24-0.27$ & $<0.001$ \\
\hline \multicolumn{4}{|l|}{ Gender } \\
\hline Male & 1 & Reference & - \\
\hline Female & 0.93 & $0.89-0.97$ & 0.001 \\
\hline \multicolumn{4}{|l|}{ Tumor size (cm) } \\
\hline$<1$ & 1 & Reference & - \\
\hline $1-2$ & 3.51 & $3.29-3.74$ & $<0.001$ \\
\hline $2-3$ & 9.36 & $8.74-10.02$ & $<0.001$ \\
\hline $3-4$ & 16.28 & $14.87-17.82$ & $<0.001$ \\
\hline $4-5$ & 16.98 & $14.74-19.56$ & $<0.001$ \\
\hline $5-6$ & 8.47 & $6.96-10.30$ & $<0.001$ \\
\hline$>6$ & 4.30 & $3.69-5.02$ & $<0.001$ \\
\hline \multicolumn{4}{|l|}{ Race } \\
\hline White/Caucasian & 1 & Reference & - \\
\hline African American & 0.68 & $0.64-0.72$ & $<0.001$ \\
\hline Asian & 0.97 & $0.86-1.11$ & 0.732 \\
\hline Other/unknown & 0.79 & $0.69-0.89$ & $<0.001$ \\
\hline \multicolumn{4}{|l|}{ Facility type } \\
\hline Community & 1 & Reference & - \\
\hline CCC & 2.95 & $2.63-3.31$ & $<0.001$ \\
\hline Integrated network & 4.44 & $3.92-5.03$ & $<0.001$ \\
\hline Academic/research & 5.82 & $5.20-6.51$ & $<0.001$ \\
\hline \multicolumn{4}{|l|}{ Charlson-Deyo } \\
\hline 0 & 1 & Reference & - \\
\hline 1 & 1.41 & $1.33-1.50$ & $<0.001$ \\
\hline 2 & 0.99 & $0.88-1.10$ & 0.785 \\
\hline 3 & 0.48 & $0.40-0.57$ & $<0.001$ \\
\hline
\end{tabular}

Abbreviations: CCC, comprehensive community cancer program; $\mathrm{Cl}$, confidence interval; OR, odds ratio; PA, pituitary adenoma. pituitary radiation, there has been a call for more conservative management of PA with endocrinological surveillance. ${ }^{4}$

With regards to the type of radiation used, there was a decline in the use of EBRT over time, with a simultaneous rise in the rates of use of SRS for PA treatment. As SRS only requires a single-radiation session, it is a more convenient option for patients. Furthermore, it has been found to have equivalent efficacy and safety when compared with EBRT. ${ }^{4,18-20}$ However, prior studies have identified a substantially lower risk of damage to the optic pathway with EBRT relative to SRS. ${ }^{21,22}$ Further studies have demonstrated that these detrimental effects are the result of doses above 8 to $10 \mathrm{~Gy}$ delivered in a single dose to optic pathway structures, ${ }^{23,24}$ suggesting that EBRT should be utilized in place of SRS in cases where an adenoma is proximal to the optic pathway, thereby increasing the risk of damage. Together, these features support the use of SRS in place of EBRT for the treatment of PA when the tumor is not in a location that would involve a risk of high doses of radiation to the optic pathway.

Overall, this analysis identifies several factors that are associated with the use of radiation therapy as part of treatment for PA. Patients with microadenomas were less likely to receive radiation therapy, likely due to higher rates of successful surgical resection or a "watchful waiting" approach to smaller and thus potentially less symptomatic adenomas. Radiation therapy use peaked for adenomas 4 to $5 \mathrm{~cm}$ in size. We hypothesize that this may be because patients with tumors larger than $5 \mathrm{~cm}$ are less likely to receive treatment of any kind due to an increased risk of morbidity or mortality associated with the intensive interventions that would be required, including a significantly higher risk of developing a new anterior pituitary deficit and a higher likelihood of recurrence. ${ }^{25,26}$ Our analysis identified a similar pattern in the treatment of PA using any type of intervention, with a peak likelihood of intervention found in tumors between 3 and $4 \mathrm{~cm}$ in size.

Females were found to more commonly receive radiation for PAs than their male counterparts. Females were also found to be younger at diagnosis than males, a finding that is consistent with other reports. ${ }^{17}$

Our analysis revealed that African Americans are less likely to undergo radiation for PA than White patients, a finding that is echoed in prior works on disparities in radiation therapy for head and neck cancers. ${ }^{27}$ Similar studies that consider additional cancer types suggest potential mechanisms for this disparity, including lower referral rates to radiation oncologists for African American patients, ${ }^{28,29}$ differences in socioeconomic status, lack of adequate health insurance, or lack of access to health care resources. ${ }^{30,31}$ A recent meta-analysis of studies on the disparities in access to radiation therapy found this racial disparity to be prevalent across multiple cancer types. ${ }^{32}$

Patients between 54 and 64 were more likely to receive radiation than those under 54 . This could be due to avoidance of radiation in younger patients due to the potential for late toxicities that it entails, having been associated with cerebrovascular disease, secondary brain tumors, and cognitive deficits. ${ }^{21,33,34}$ This finding may also be related to the use of radiation therapy for pituitary adenomas that have recurred, an event that is more likely in older patients. 


\section{Limitations}

Limitations of this study are inherent to a retrospective analysis. As with any cross-institutional database, the NCDB may be limited by inconsistencies in data collection and reporting across participating hospitals. While the NCDB provides a wide array of tumor and patient data, it does not collect or report on patient symptoms at presentation or whether PAs were identified incidentally, precluding a comparison between symptomatic adenomas and "incidentalomas." Similarly, because the NCDB does not collect data on the secretory status of PAs, we were not able to stratify our analysis by functional tumor status.

\section{Conclusion}

This study identified increasing rates of pituitary adenoma diagnosis between 2004 and 2014. Additionally, we observed a progressive decline in the rate of radiation therapy in pituitary adenoma treatment in this time period, as well as an overall decrease, in the use of any treatment as initial therapy for pituitary adenoma. These findings can inform treatment decisions and guide the use of radiation therapy for pituitary adenomas moving forward.

\section{Conflict of Interest}

None declared.

\section{References}

1 Laws ER Jr., Ebersold MJ, Piepgras DG, Randall RV, Salassa RM. The results of transsphenoidal surgery in specific clinical entities. In: Management of Pituitary Adenomas and Related Lesions with Emphasis on Transsphenoidal Microsurgery. New York, NY: Appleton-Century-Crofts Inc.; 1982:277-305

2 Laws ER Jr., Vance ML. Radiosurgery for pituitary tumors and craniopharyngiomas. Neurosurg Clin N Am 1999;10(02): 327-336

3 Sheehan JP, Xu Z, Lobo MJ. External beam radiation therapy and stereotactic radiosurgery for pituitary adenomas. Neurosurg Clin N Am 2012;23(04):571-586

4 Loeffler JS, Shih HA. Radiation therapy in the management of pituitary adenomas. JClin Endocrinol Metab 2011;96(07): 1992-2003

5 Nilsson B, Gustavasson-Kadaka E, Bengtsson BA, Jonsson B. Pituitary adenomas in Sweden between 1958 and 1991: incidence, survival, and mortality. JClin Endocrinol Metab 2000;85(04): 1420-1425

6 Shibui S. [The present status and trend of brain tumors based on the data of the Brain Tumor Registry of Japan]. Brain Nerve 2012; 64(03):286-290

7 Dolecek TA, Propp JM, Stroup NE, Kruchko C. CBTRUS statistical report: primary brain and central nervous system tumors diagnosed in the United States in 2005-2009. Neuro-oncol 2012;14 (Suppl 5):v1-v49

8 Aflorei ED, Korbonits M. Epidemiology and etiopathogenesis of pituitary adenomas. J Neurooncol 2014;117(03):379-394

9 Davis FG, Kupelian V, Freels S, McCarthy B, Surawicz T. Prevalence estimates for primary brain tumors in the United States by behavior and major histology groups. Neuro-oncol 2001;3(03): 152-158

10 Ezzat S, Asa SL, Couldwell WT, et al. The prevalence of pituitary adenomas: a systematic review. Cancer 2004;101(03):613-619
11 Fernández-Balsells MM, Murad MH, Barwise A, et al. Natural history of nonfunctioning pituitary adenomas and incidentalomas: a systematic review and metaanalysis. JClin Endocrinol Metab 2011;96(04):905-912

12 Nammour GM, Ybarra J, Naheedy MH, Romeo JH, Aron DC. Incidental pituitary macroadenoma: a population-based study. Am J Med Sci 1997;314(05):287-291

13 Yue NC, Longstreth WT Jr., Elster AD, Jungreis CA, O'Leary DH, Poirier VC. Clinically serious abnormalities found incidentally at MR imaging of the brain: data from the Cardiovascular Health Study. Radiology 1997;202(01):41-46

14 Hartwigsen G, Siebner HR, Deuschl G, Jansen O, Ulmer S. Incidental findings are frequent in young healthy individuals undergoing magnetic resonance imaging in brain research imaging studies: a prospective single-center study. J Comput Assist Tomogr 2010;34 (04):596-600

15 Vernooij MW, Ikram MA, Tanghe HL, et al. Incidental findings on brain MRI in the general population. N Engl J Med 2007;357(18): 1821-1828

16 Ryu WH, Tam S, Rotenberg B, et al. Conservative management of pituitary macroadenoma contacting the optic apparatus. Can J Neurol Sci 2010;37(06):837-842

17 Iglesias P, Arcano K, Triviño V, et al. Prevalence, clinical features, and natural history of incidental clinically non-functioning pituitary adenomas. Horm Metab Res 2017;49(09):654-659

18 Powell JS, Wardlaw SL, Post KD, Freda PU. Outcome of radiotherapy for acromegaly using normalization of insulin-like growth factor I to define cure. JClin Endocrinol Metab 2000;85(05): 2068-2071

19 Mitsumori M, Shrieve DC, Alexander E III, et al. Initial clinical results of LINAC-based stereotactic radiosurgery and stereotactic radiotherapy for pituitary adenomas. Int J Radiat Oncol Biol Phys 1998;42(03):573-580

20 Landolt AM, Haller D, Lomax N, et al. Stereotactic radiosurgery for recurrent surgically treated acromegaly: comparison with fractionated radiotherapy. JNeurosurg 1998;88(06): 1002-1008

21 Brada M, Rajan B, Traish D, et al. The long-term efficacy of conservative surgery and radiotherapy in the control of pituitary adenomas. Clin Endocrinol (Oxf) 1993;38(06):571-578

22 Erridge SC, Conkey DS, Stockton D, et al. Radiotherapy for pituitary adenomas: long-term efficacy and toxicity. Radiother Oncol 2009;93(03):597-601

23 Tishler RB, Loeffler JS, Lunsford LD, et al. Tolerance of cranial nerves of the cavernous sinus to radiosurgery. Int J Radiat Oncol Biol Phys 1993;27(02):215-221

24 Mayo C, Martel MK, Marks LB, Flickinger J, Nam J, Kirkpatrick J. Radiation dose-volume effects of optic nerves and chiasm. Int J Radiat Oncol Biol Phys 2010;76(3, Suppl):S28-S35

25 Pollock BE, Cochran J, Natt N, et al. Gamma knife radiosurgery for patients with nonfunctioning pituitary adenomas: results from a 15-year experience. Int J Radiat Oncol Biol Phys 2008;70(05): 1325-1329

26 Sheehan JP, Starke RM, Mathieu D, et al. Gamma Knife radiosurgery for the management of nonfunctioning pituitary adenomas: a multicenter study. J Neurosurg 2013;119(02):446-456

27 Park HS, Decker RH. Disparities in radiation therapy delivery: current evidence and future directions in head and neck cancer. Cancers Head Neck 2016;1(01):5

28 Vinod SK, Simonella L, Goldsbury D, Delaney GP, Armstrong B, O'Connell DL. Underutilization of radiotherapy for lung cancer in New South Wales, Australia. Cancer 2010;116(03):686-694

29 Goulart BHL, Reyes CM, Fedorenko CR, et al. Referral and treatment patterns among patients with stages III and IV non-smallcell lung cancer. J Oncol Pract 2013;9(01):42-50

30 Freeman HP, Chu KC. Determinants of cancer disparities: barriers to cancer screening, diagnosis, and treatment. Surg Oncol Clin N Am 2005;14(04):655-669, v 
294 Radiation for Pituitary Adenoma in the NCDB Fathy et al.

31 Gerend MA, Pai M. Social determinants of Black-White disparities in breast cancer mortality: a review. Cancer Epidemiol Biomarkers Prev 2008;17(11):2913-2924

32 McClelland S, Deville C, Thomas CJr, Jaboin JJ. An overview of disparities research in access to radiation oncology care. J Radiat Oncol 2016;5(04):437-444
33 Rieken S, Habermehl D, Welzel T, et al. Long term toxicity and prognostic factors of radiation therapy for secreting and nonsecreting pituitary adenomas. Radiat Oncol 2013;8(01):18

34 Solda F, Fersht T. Radiotherapy for pituitary tumours. In: De Groot LJ, Chrousos G, Dungan K, et al. Endotext [Internet]. South Dartmouth, MA2000 